\title{
RESEARCH
}

Open Access

\section{Characterization of smallholder cattle production systems in South-Kivu province, eastern Democratic Republic of Congo}

Yannick Mugumaarhahama* ${ }^{*}$, Rodrigue Balthazar Basengere Ayagirwe, Valence Bwana Mutwedu, Nadège Cizungu Cirezi, Dieudonné Shukuru Wasso, Pascaline Ciza Azine and Katcho Karume

\begin{abstract}
In South-Kivu province, cattle farming is an integral component of farmers' livelihoods and one of the few incomegenerating opportunities for smallholders. However, very few studies have been conducted to characterize smallholders' cattle production systems. This study documents cattle production systems to better understand their current situation, constraints they face and opportunities they offer. For that purpose, an investigation was conducted based on a structured survey questionnaire and participatory interviews with 863 farmers in South-Kivu province. Collected data were analysed using factorial analysis of mixed data and clustering techniques. The results revealed three types of smallholder cattle farms differing mainly in their herds' sizes and landholding. The first category is the most common and includes farmers raising small herds (6.3 \pm 6.7 cattle) of local breeds in herding system (in this work, "herding system" refers to a rearing system for which the farmer drives and stays with his animals on pastures and fallow land during the day) and grazing fodder in community pastures, fallow lands and roadside grasses, while land constitutes a scarce resource. In the second category, some farmers have small tracts of land ( $<5 \mathrm{ha}$ ) and others have large tracts ( $>5 \mathrm{ha}$ ), but all have medium-size herds ( $45.1 \pm 19.4$ cattle) made up of local breeds, which they rear in herding system. They also exploit community pastures, fallow land and roadside fodder for animal feeding. The third and last category includes farmers with large cattle herds (78.1 \pm 28.1 cattle) of local, crossbred and exotic breeds raised free range in the fenced paddocks on vast areas of land ( $>5 \mathrm{ha}$ ) found in high-altitude regions. However, while being different according to the above-considered characteristics, the three categories of cattle farming remain extensive pastoral farms dominated by male farmers. Agriculture and/or animal husbandry are their main source of income while their livestock are also composed of goats and poultry, beside cattle. Still, the three farming groups require more inputs and improvement strategies for increased productivity in the challenging environment characterized by low land accessibility and high demand for milk and meat. Fodder cultivation and crop-livestock integration through agro-ecological systems as well as access to credit and extension services are the proposed strategies for the improvement of this economic sector.
\end{abstract}

Keywords: Clustering analysis, Factorial analysis of mixed data, Farmers typology, Pastoralism

\footnotetext{
* Correspondence: mugumaarhahama@uea.ac.cd

Faculty of Agriculture and Environmental Sciences, Université Evangélique en Afrique, PO Box 3323, Bukavu, Democratic Republic of the Congo
}

\section{Springer Open}

(๑) The Author(s). 2021 Open Access This article is licensed under a Creative Commons Attribution 4.0 International License, which permits use, sharing, adaptation, distribution and reproduction in any medium or format, as long as you give appropriate credit to the original author(s) and the source, provide a link to the Creative Commons licence, and indicate if changes were made. The images or other third party material in this article are included in the article's Creative Commons licence, unless indicated otherwise in a credit line to the material. If material is not included in the article's Creative Commons licence and your intended use is not permitted by statutory regulation or exceeds the permitted use, you will need to obtain permission directly from the copyright holder. To view a copy of this licence, visit http://creativecommons.org/licenses/by/4.0/. 


\section{Introduction}

Africa is predominantly rural, with $54 \%$ of the population engaged in agriculture (Kuivanen et al. 2016). Farming remains the most predominant livelihood activity and source of income of sub-Saharan African (SSA) rural households (Davis et al. 2017). Most food production comes largely from small, fragmented plots of land owned by smallholders, making their production a key player in the continent's rural economy (Wiggins 2009). Furthermore, livestock is valuable in sustainable agriculture by providing manure and labour for increased productivity and therefore enhancing the well-being and increased income of farmers in SSA (Lammers et al. 2009; Swanepoel et al. 2010; Herrero et al. 2013; Mutwedu et al. 2015; Mugumaarhahama et al. 2016; Akilimali et al. 2017; Mugumaarhahama et al. 2020).

In SSA, the milk value chain boosts the local community economy by providing employment and milk industry development (Seré et al. 2008; McDermott et al. 2010; Chagunda et al. 2016), safeguards food security and enhances access to animal protein (Hemme and Otte 2012). This is highly observed in a mixed croplivestock system, as two thirds of smallholders in East and Central Africa rely on mixed crop-livestock systems (Herrero et al. 2013).

In DR Congo, smallholder farming systems are diverse, mostly with livestock as an integral part of the system (Cox 2012). Livestock contributes up to $9.2 \%$ of the gross domestic product and plays a crucial role in the livelihood of the local population. Cattle, which is the most reared livestock and the most consumed in the country, contributes to more than $50 \%$ of the total meat consumption. However, the current national cattle herd estimated at 40 million head remains far below the country's potential $(2.3 \%$ of the 1.75 billion head production potential) (SNSA 2014). Because of increasing demand for animal source foods, desire to reduce poverty and the environmental impact of livestock production, tropical livestock farming systems must increase their productivity (Oosting et al. 2014).

However, research conducted in DR Congo has shown that current cattle herd sizes are still insufficient due to pressure on resources, high population density and poverty (Cox 2012) as a consequence of recent violent conflicts (Maass et al. 2012). The prospects for achieving sustainable intensification of smallholder farming systems need to be examined in relation to the dominant typologies of farmers, to inform the development of effective and appropriate interventions (Mutyasira 2020).

In South-Kivu province, agricultural production has decreased in the past decade of turmoils (Maass et al. 2012; Mutwedu et al. 2015; Akilimali et al. 2017), leading to a vicious cycle of low food production and insecurity
(Rossi et al. 2006; Kandala et al. 2011). Therefore, livestock production, especially of cattle, remains one of the few available opportunities for income generation at the household level (Maass et al. 2012). However, very few studies have been conducted to characterize the smallholders' cattle production systems in SouthKivu. This is crucial, especially in rural areas where cattle production has been a very critical integral component of farmers' livelihoods (Maass et al. 2012). The characterization of smallholders' cattle production systems will contribute to better understanding of their current situation, the constraints they face and the opportunities they offer, and highlight potential hotspots for productivity improvement (Mugumaarhahama et al. 2020). The generated cattle farming types will serve as a basis for future research, since this existing gap of cattle farming classification is documented here. This study intended to characterize the smallholders' cattle production systems in rural areas of South-Kivu, DR Congo, and analyse its impact on the performances and reproductive parameters of raised cattle.

\section{Methods \\ Study area}

This study was carried out in South-Kivu province, eastern DR Congo (Fig. 1). This province is located between $1^{\circ} 36^{\prime}$ and $5^{\circ}$ south latitude and between $26^{\circ} 47^{\prime}$ and $29^{\circ}$ $20^{\prime}$ east longitude. It covers an area of $69,130 \mathrm{~km}^{2}$ and has an average annual temperature of $19^{\circ} \mathrm{C}$, with an altitude ranging from 773 to $3000 \mathrm{~m}$ a.s.l.

\section{Sampling and data collection}

Sampling was conducted in seven of the eight territoires ${ }^{1}$ of South-Kivu province (Kabare, Walungu, Uvira, Kalehe, Mwenga, Fizi and Idjwi) and data collected from 863 cattle farms. The investigations were not extended to Shabunda due to limited access to this territoire.

In each farm, a structured survey questionnaire and participatory interviews were carried out with farm managers. The questionnaire was administered in the local language through face-to-face interviews. The gathered information mainly covered farmer's socio-demographic information, herd characteristics and main livestock management practices.

\section{Estimation of production performance Live weight}

The live weight of the cattle was estimated based on the chest circumference by using rondo tape. In each farm, the live weight was estimated on 2 to 5 cattle aged at

${ }^{1}$ In the South-Kivu province, administrative units are, from superior to inferior, territoire, collectivité, groupement, localité and village. 


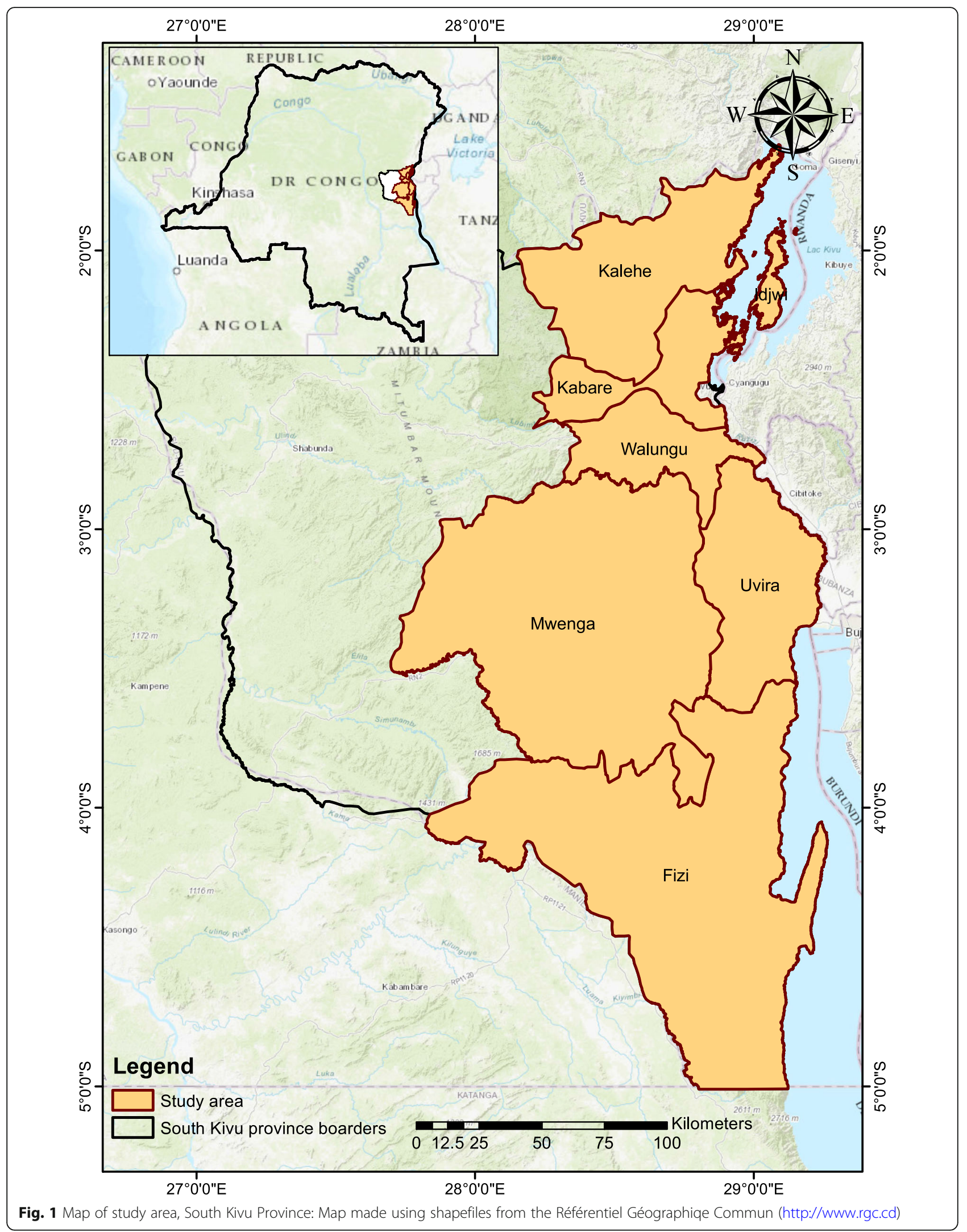


least 24 months. Since females were more predominant in the herds, weight measurements were only made on them.

\section{Quantity of milk produced per female}

To estimate the quantity of milk produced per female per day, graduated containers were used. Whenever the farmer gave his consent, the container used to collect fresh milk of a cow was poured with a quantity of water almost equivalent to that of the milk (previously poured into another container). This water was then poured into the graduated container in order to estimate its quantity and deduct the quantity of milk. If possible, this operation was done on 2 to 5 females in each farm.

\section{Data analysis}

Multivariate statistical analyses are commonly used to identify explanatory variables that can help in grouping individuals into homogenous groups. For this particular case, the analysis primarily helped in grouping farms into homogeneous clusters that represent farm types. Following the workflow presented in Fig. 2, data reduction method was applied on a selected set of variables to derive a smaller set of non-correlated principal components. Then, clustering techniques were used to the coordinates of the farms on these new axes. Factorial analysis of mixed data (FAMD) was applied, a data reduction technique for categorical and quantitative variables. Although the number of key variables is reduced, the variability of the dataset is largely preserved (Alvarez et al. 2018). The core idea common to all principal component methods such as FAMD is to describe a dataset using a small number of uncorrelated variables while retaining as much information as possible. In FAMD, the reduction is achieved by transforming the dataset containing categorical and quantitative variables into a new set of continuous variables (principal components) (Husson et al. 2010). The FAMD output in the form of a reduced dataset based on the retained principal components was subjected to clustering analysis (CA). CA was applied to these principal components to identify clusters that minimize variability within clusters and maximize differences between clusters. A two-step approach was followed: agglomerative hierarchical clustering and non-hierarchical clustering (partitioning around medoids), such as $k$-means. At the time, both clustering methods are used to combine the strengths of the two approaches (see, e.g. Michielsens et al. 2002; Iraizoz et al. 2007; Kuivanen et al. 2016). Agglomerative hierarchical clustering algorithm using Ward's method was employed to define the optimal number of groups $(k)$, and then a non-hierarchical ( $k$-means) partitioning algorithm was employed to refine these $k$-groups. Ward's method resulted in a range of cluster solutions, where each observation started out as its own cluster and was successively joined by similar clusters until only a single cluster remained (Reynolds et al. 2006). This agglomerative nesting process was represented by a dendrogram. In determining the optimal cluster cut-off points, a trade-off was sought between the number of clusters and the level of dissimilarity between clusters, with the objective of maximizing both intra-cluster homogeneity and inter-cluster heterogeneity (Hair et al. 2010). The number of clusters retained from Ward's method was used as a starting value by the non-hierarchical algorithm, which was performed to improve the robustness of the classification by optimizing farm distribution among clusters so as to minimize the sum of the distances of each observation from its cluster centre (Reynolds et al. 2006). To characterize the final set of clusters, they were examined in terms of their inherent structure (i.e. descriptive statistics of each variable for each cluster).

To determine the socio-economic factors influencing the adoption of exotic breeds and those influencing herds' size, the logit logistic regression and Poisson regression were used, respectively. The predictor variables used in these models are age, sex, experience of the farmer in cattle farming, marital status, the main source of income, level of education, geographical location of the farm (agro-ecological zone), grazing system practised and landholding size.

In this study, statistical analyses were performed under R, version 3.5.1 (R Development Core Team 2018). Factorial analysis of mixed data (FAMD) and hierarchical clustering on principal components (HCPC) were the main analyses conducted for this study using the package FactoMineR (Lê et al. 2008). We used FAMD to obtain maps showing distances between quantitative variables and the categories (modalities) of the qualitative variables and between the observations and to have quantitative synthetic variables (principal components) that were then used for clustering. In FAMD, only the first axes are retained to stabilize the clustering by deleting the noise from the data (Husson et al. 2010). To retain as much as possible the variability in the data, we have chosen to do clustering using the first seven principal components, which account for $70.898 \%$ of the total inertia of the data.

\section{Results}

\section{Factorial analysis of cattle farm information}

Factor analysis of the mixed data (FAMD) yielded 19 orthogonal principal components, first seven of which had eigenvalues greater than or equal to 1 (Table 1). Based on the Kaiser criterion, only these seven principal components were selected for use in the clustering analysis. After performing the classification, the correlation ratio 


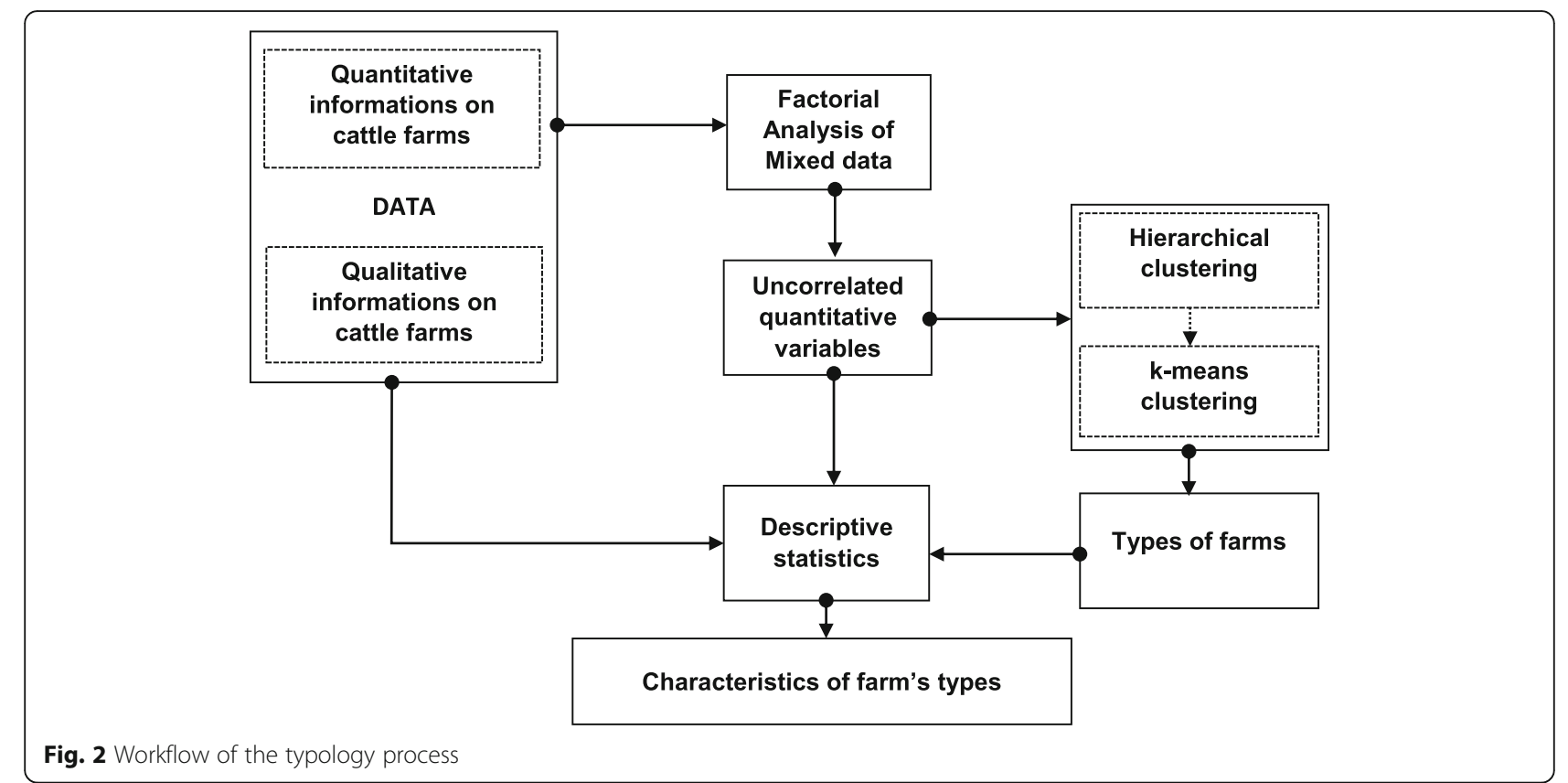

test showed that only five principal components were significantly related to the obtained clusters of cattle farms. The first two axes have correlation ratio values greater than 0.50 , which means the first factorial plane best characterizes the results of the typology. For reasons of consistency, only the results of the first two main axes are presented in the remainder of this work.

Figure 3 presents the results of the factor analysis of qualitative and quantitative information on cattle farm. The first axis (Dim.1) retains more than $28 \%$ of the total inertia (Table 1) and shows very strong correlations with the herds' size variables. It allows the best possible separation of cattle farms according to their numerical composition. It contrasts cattle farms with large herd sizes (left side of the axis) with other types of cattle farms. Free-range cattle farms in the fenced paddocks take strong coordinates on this axis, in contrast to the other cattle farming systems. This means that free-range cattle farms raised in paddocks (In this study, "paddocks" are plots of land delimited by fences on which farmers let their cattle graze freely) have a strong tendency to have large herd sizes. This seems not to be the case in the other farming systems, which in fact seems to be the most common in the region (because they are close to the centre of the main map). The second axis (Dim.2) accounts for nearly $12 \%$ of total inertia (Table 1) and makes it possible to characterize the different cattle rearing systems. This axis shows that it is very common to find hybrid cattle and those of exotic breeds in the same herds, raised mainly in a free-range system.

Using the coordinates of the individuals on the principal axes in the clustering analysis has revealed the existence of three types of cattle farming system in South-Kivu (Fig. 4). Figure 5 shows the proportion of the different types of cattle breeding system in the whole province.

Most cattle farms in South-Kivu have similar characteristics and can therefore be grouped in a unique cluster: type $1(70.80 \%)$. In addition to this cluster, there are also others, much less represented, which can be grouped into two distinct types of cattle farms. Figure 6

Table 1 Principal components obtained with FAMD and their link with the clustering analysis

\begin{tabular}{llllll}
\hline & Eigen value & Percentage of variance & Cumulative percentage of variance & $\boldsymbol{R}^{\mathbf{2}}$ & $\boldsymbol{P}_{\text {value }}$ \\
\hline Dim.1 & 6.030 & 28.715 & 28.715 & 0.757 & 0.000 \\
Dim.2 & 2.512 & 11.962 & 40.677 & 0.601 & 0.000 \\
Dim.3 & 1.678 & 7.990 & 48.668 & 0.063 \\
Dim.4 & 1.406 & 6.696 & 55.364 & 0.000 \\
Dim.5 & 1.225 & 5.835 & 61.199 & 0.027 \\
Dim.6 & 1.025 & 4.879 & 66.078 & 0.008 \\
Dim.7 & 1.012 & 4.820 & 70.898 & 0.000 \\
\hline
\end{tabular}




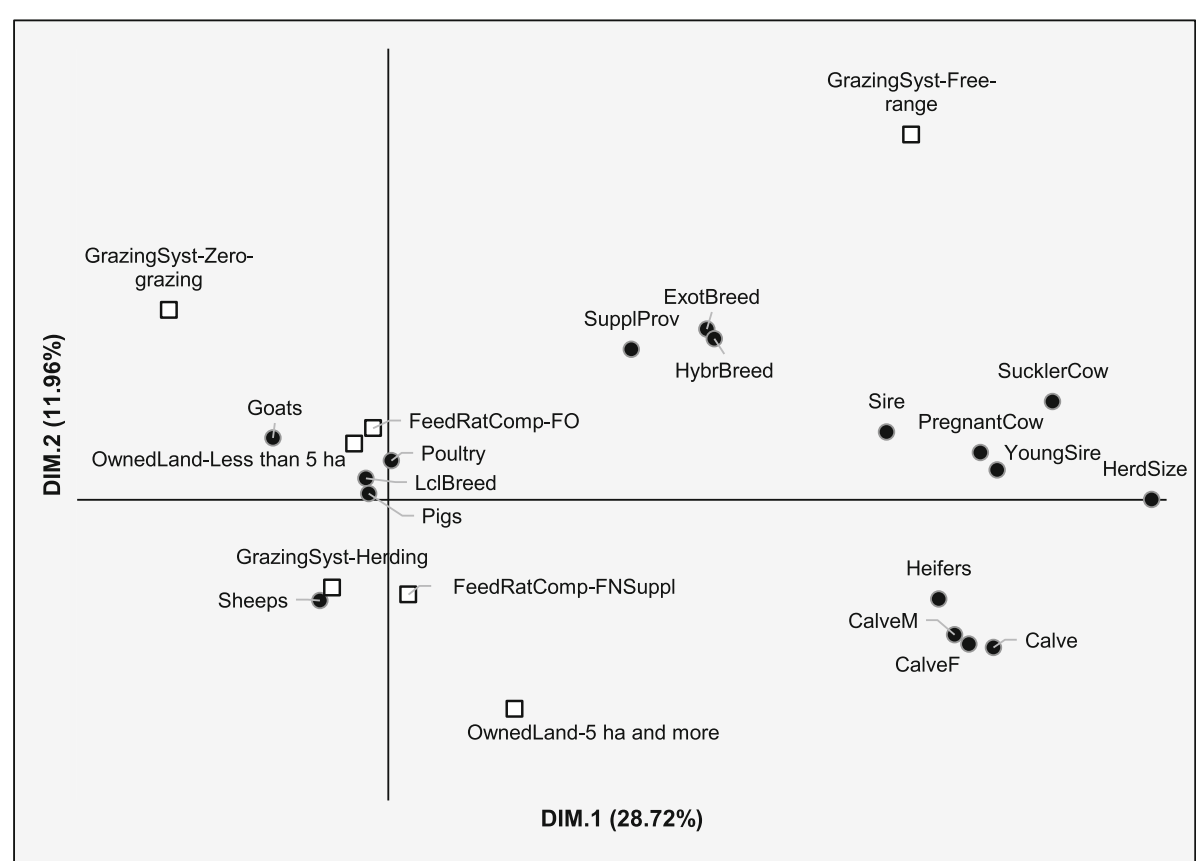

Fig. 3 Projection of modalities (squares) and quantitative variables (dots) in the main plane (Dim.1-Dim.2)

presents the characteristics of the three types of cattle farms on the main plan (Dim.1-Dim.2) obtained with the FAMD.

The results in Fig. 6 show that type 1 farms are closer to the origin of the main plan. These are therefore the most common cattle farms encountered in South-Kivu. They are small herd sizes, often reared in association with goats, and for which farmers have limited access to land. Farmers own small-sized plots, less than 5 ha. Type 2 farms take positive coordinates on the first axis
(Dim.1) and negative coordinates on the second axis (Dim.2). These are cattle farms that practise a herding (caretakerage) system, with medium-sized herds. In this category, we find farmers owning the largest amount of land. Finally, Type 3 farms take positive coordinates on both axes, meaning that these farms have large herd sizes in which exotic and/or hybrid cattle breeds are found. In these farms, cattle are raised in a free-range system. Table 2 presents the characteristics of cattle farm's types.

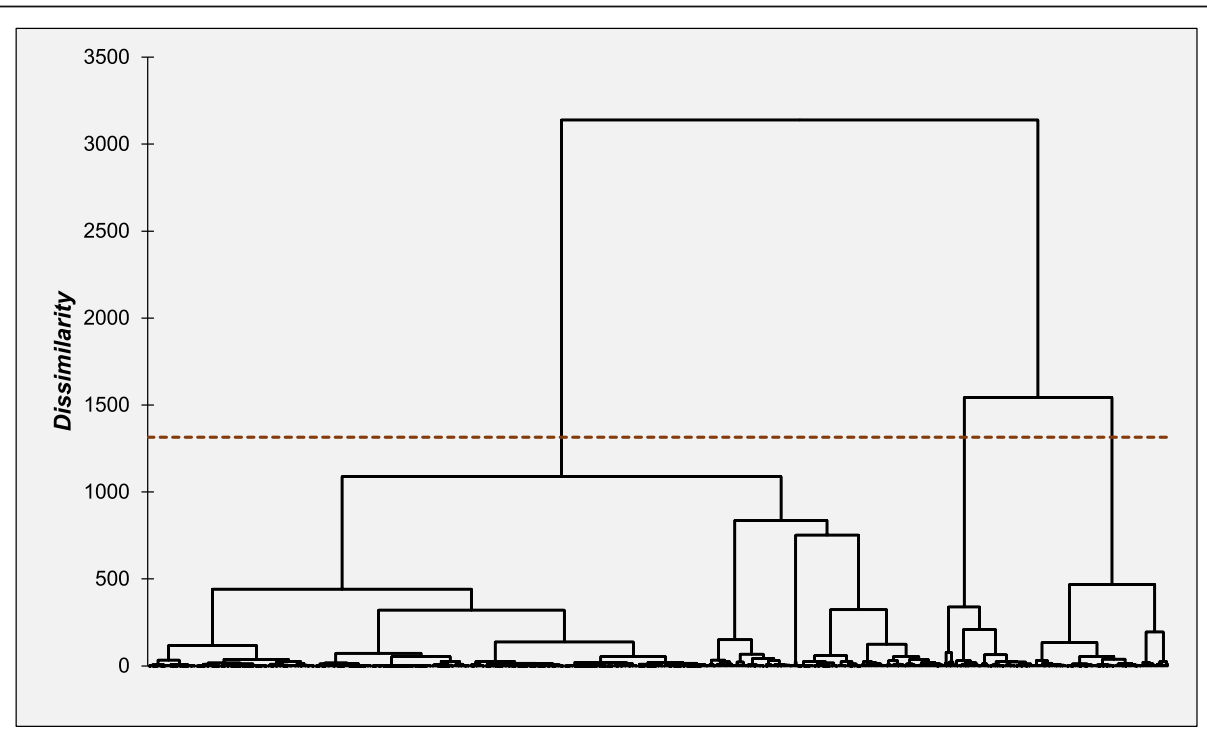

Fig. 4 Dendrogram displaying optimal solution of clustering analysis using Ward's method. Left = type 1; middle = type 2; right = type 3 


\section{Common characteristics of cattle farms encountered in South-Kivu}

In South-Kivu province, cattle are mainly raised by married male farmers who are mostly heads of household, ageing $46.2 \pm 14.2$ years old and have extensive experience in cattle farming (14.4 \pm 10.9 years). Most of them have at least a primary education and agriculture and/or cattle, goat and poultry farming are their main source of income for household subsistence. They mainly raise local cattle for milk production and live cattle that are sold for income generation, and furthermore used for the household's expenditures. Most of them experience scarcity of land and therefore allocate the small available land for both livestock and food crop production, leading them to graze their cattle on community pastures and fallow land.

Type 1: Small herds cattle farms (70.80\%) These farms have small herds of cattle, generally not exceeding 40 heads of local breed. They are found both in high- and low-altitude zones. The basic feeding resources are mainly forage grazed in community pastures and/or fallow land. Farmers in this category hold small tracts of land (much less than $5 \mathrm{ha}$ ), on which they prefer growing forest tree species or food crops. The herd is dominated by suckler cows, pregnant cows and sires. It is also the type of farm with the lowest production in terms of animal weight $(261.5 \pm 56.2 \mathrm{~kg})$ and milk production $(1.8 \pm$ $0.8 \mathrm{l} /$ cow/day). The total number of cattle raised in this type of farm represents only $21.8 \%$ of the total herd in South-Kivu province.

Type 2: Medium herds cattle farms (20.63\%) These are also farms rearing cattle in herding (caretakerage) systems. They are mostly encountered in the midaltitude zones, with herd size comprised between 20 and 126 heads of local breed cattle, occasionally associated which crossbred and/or exotic breeds. The main categories of cattle in these herds are lactating cows, pregnant cows, heifers and calves. The basic feed consists of pasture with some supplements to meet the animal nutritional requirements. In this category of farms, access to land is variable; some have large tracts of land (more than 5 ha) mostly used as pasture while others experience limited access to land, constraining them to rely on community pastures and/or fallow land for animal grazing. In this category of cattle farms, production record is slightly higher compared to type 1 for adult female weighing $(311.3 \pm 88.9 \mathrm{~kg})$, while milk production is comparable in both production systems $(1.7 \pm 0.7 \mathrm{l} / \mathrm{cow} /$ day). The total number of cattle raised under this type of farm represents the largest proportion of the total herd in South-Kivu province (45.5\%).
Type 3: Large herds cattle farms (8.57\%) This type of cattle farming is carried out by farmers who mostly have large tracts of land (more than $5 \mathrm{ha}$ ) which allow them to raise a large number of cattle in a free-range system or in paddocking. Cattle raised under this system are left to wander around paddocks, and farmers take care to rotate the paddocks regularly for range management. Thus, the feed ration consists of pasture only; nevertheless, farmers provide feed supplements, mainly mineral and salts. These farms are almost exclusively found in high-altitude areas, and generally, flock size varies from 41 to 182 heads of cattle of different breeds (local, crossbred and exotic breeds) and are mainly savings on the farm for most of the farmers who own them. Seemingly, the introduction of exotic breeds of cattle has improved production performance. On average, an adult cow produced under this type of farm weighs $362.3 \pm 87.3 \mathrm{~kg}$ and produces $4.6 \pm 2.9 \mathrm{l} /$ day. Cattle raised in this type of farm represents $32.7 \%$ of the total herd in South-Kivu province.

\section{Socio-economic determinants of adoption of exotic breeds and herd sizes}

The results from Table 3 identify three determinants of adoption of exotic breeds of cattle in South-Kivu: the location of the farm (agro-ecological zone), the source of income and the grazing system practised. Livestock farmers in high-altitude zones are more likely to adopt exotic breeds than those in medium-altitude zones. Farmers whose income is mainly off-farm are also the most likely to adopt exotic breeds. Finally, farmers practising free-range grazing system within paddocks are more likely to adopt exotic breeds than those who do herding and zero-grazing systems. It should be noted that women involved in cattle farming tend to be more open to the adoption of exotic breeds compared to male farmers.

As far as the determinants of the size of cattle herds are concerned, almost all the covariates included in the model showed a strong link with the cattle herd size. The results from Table 3 show that the older the farmer is and the more experience he has in cattle farming, the smaller is the size of his cattle herd. On the other hand, the higher the education level of the farmer, the larger the cattle herd, and the higher the altitude, the larger the cattle herd. It is also noted that the cattle herds belonging to the few women involved in cattle farming are larger than those of male farmers. As far as marital status is concerned, widowed or divorced farmers have smaller cattle herds than those of farmers who are still in married life. In addition, the fact of having off-farm incomes plays in favour of increasing the herd size. Livestock farmers with off-farm income have larger herds than those with only farming and/or livestock as their 


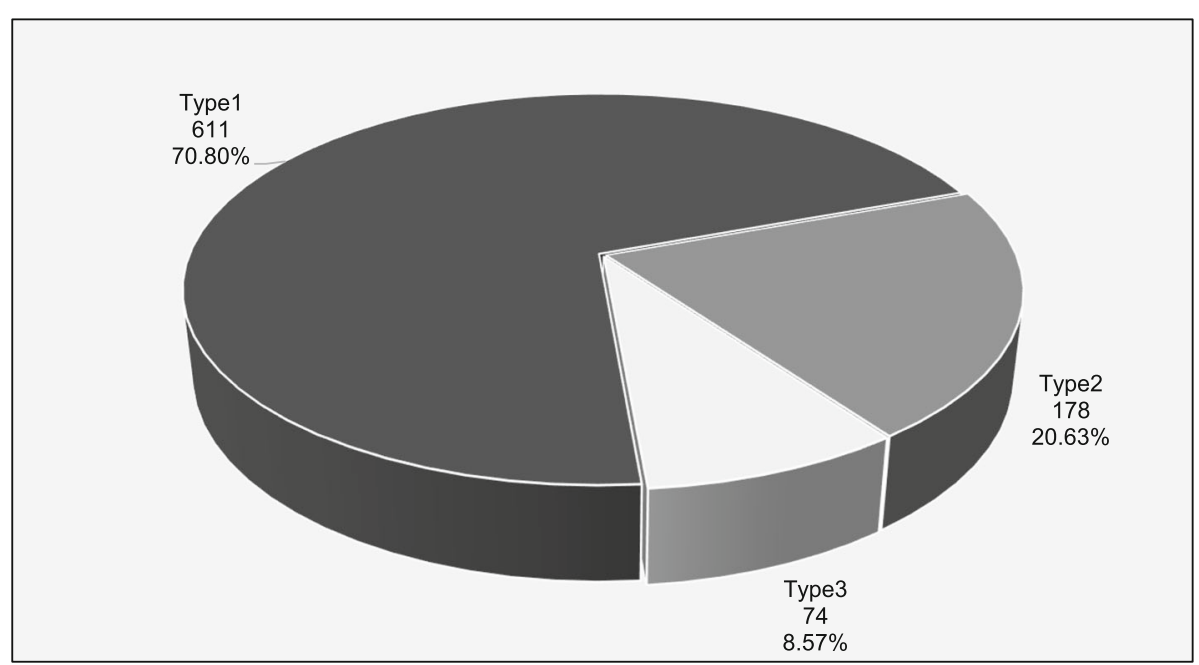

Fig. 5 Proportion of different types of cattle farming system in South-Kivu

main income source. Cattle herds are much larger in the free-range paddock system and much less in zerograzing system. Finally, herd size is closely related to the amount of land owned. The larger the land area, the larger is the herd.

\section{Discussion}

This study aimed at understanding the diversity within the South-Kivu province cattle farms and the mechanisms underlying it. The results show that the cattle farms in South-Kivu province are heterogeneous. This study shows the existence of three types of cattle farming systems whose main distinguishing characteristics are geographical location, the age of the farmers and their experience in cattle farming, the farming system, the breeds of cattle, the size of landholding and the size of the herds. Nevertheless, it is difficult to fully capture the diversity of cattle farming systems as experienced as well by Kuivanen et al. (2016), and we are aware of the limitations of the typology in this regard.

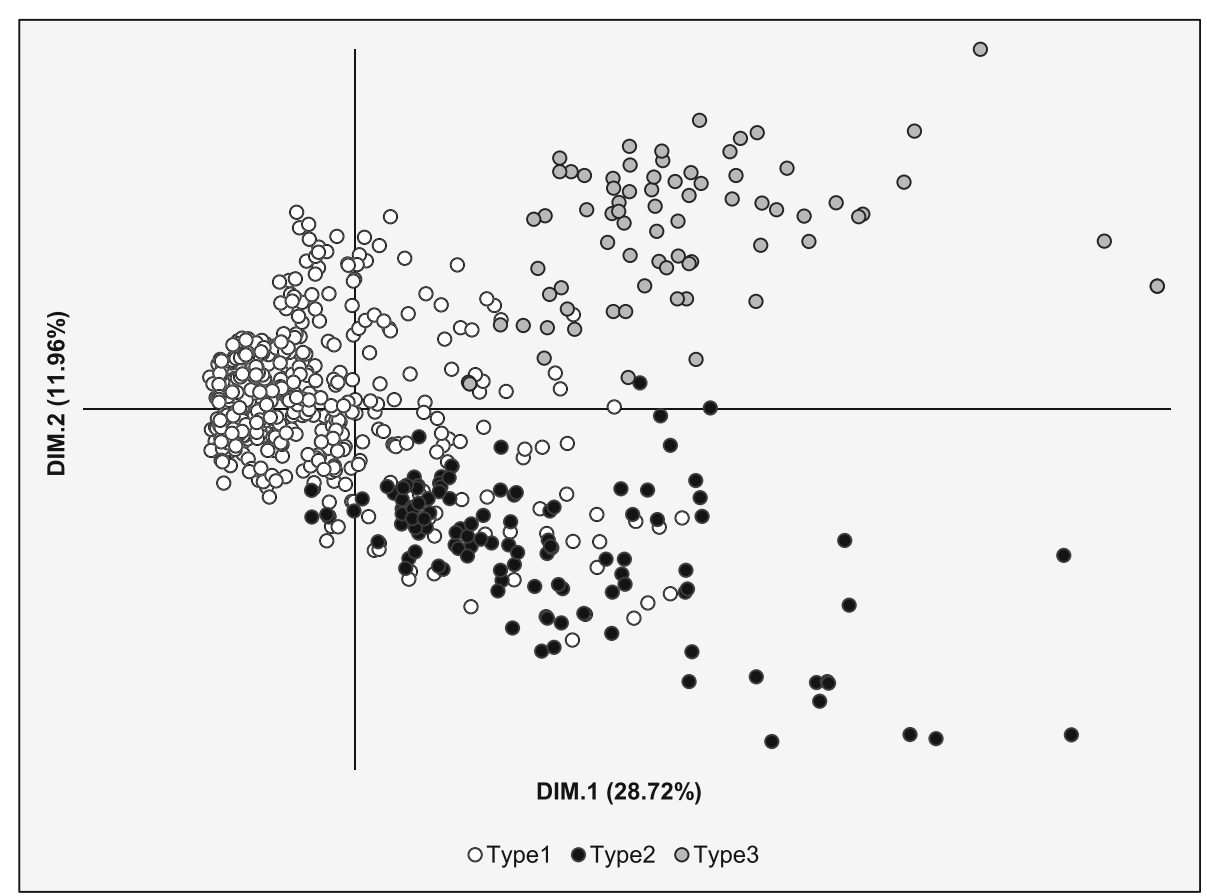

Fig. 6 Projection of cattle farms on the main plan (Dim.1-Dim.2) according to their typology 
Table $\mathbf{2}$ Characteristics of cattle farm's types

\begin{tabular}{|c|c|c|c|c|}
\hline & Type1 & Type2 & Type3 & Total \\
\hline \multicolumn{5}{|l|}{ Agro-ecological zone (AEZ) (\%) } \\
\hline Medium altitude & 42.8 & 97.7 & 1.4 & 50.2 \\
\hline High altitude & 57.2 & 2.3 & 98.6 & 49.8 \\
\hline \multicolumn{5}{|l|}{ Gender (\%) } \\
\hline Woman & 4.5 & 3.5 & 13.7 & 5.1 \\
\hline Man & 95.5 & 96.5 & 86.3 & 94.9 \\
\hline \multicolumn{5}{|l|}{ Marital status (\%) } \\
\hline Divorced & 0.5 & 0.0 & 1.4 & 0.5 \\
\hline Married & 99.0 & 100.0 & 98.6 & 99.2 \\
\hline Widow & 0.5 & 0.0 & 0.0 & 0.3 \\
\hline \multicolumn{5}{|l|}{ Schooling level (\%) } \\
\hline Illiterate & 26.0 & 8.8 & 9.6 & 21.2 \\
\hline Primary & 29.4 & 33.3 & 28.8 & 30.1 \\
\hline Secondary & 42.0 & 56.7 & 56.2 & 46.1 \\
\hline University & 2.6 & 1.2 & 5.5 & 2.5 \\
\hline \multicolumn{5}{|l|}{ Main source of income (\%) } \\
\hline Livestock/agriculture & 86.9 & 85.4 & 75.5 & 85.7 \\
\hline Off-farm activity & 13.1 & 14.6 & 24.6 & 14.3 \\
\hline Age (years) & $47.3 \pm 15.0$ & $44.3 \pm 13.2$ & $41.0 \pm 6.3$ & $46.2 \pm 14.2$ \\
\hline Experience in cattle farming (years) & $15.3 \pm 11.3$ & $14.3 \pm 9.8$ & $7.3 \pm 7.0$ & $14.4 \pm 11.0$ \\
\hline \multicolumn{5}{|l|}{ Grazing system (\%) } \\
\hline Herding & 76.7 & 98.8 & 21.9 & 76.5 \\
\hline Free range in paddocks & 10.2 & 0.6 & 63.0 & 12.7 \\
\hline Zero-grazing & 13.1 & 0.6 & 15.1 & 10.8 \\
\hline \multicolumn{5}{|l|}{ Other livestock raised (\%) } \\
\hline Goat & 91.8 & 68.4 & 100.0 & 87.8 \\
\hline Pig & 47.7 & 44.4 & 47.9 & 47.0 \\
\hline Poultry & 86.3 & 78.4 & 100.0 & 85.9 \\
\hline Sheep & 20.0 & 28.7 & 0.0 & 20.0 \\
\hline \multicolumn{5}{|l|}{ Cattle breeds raised (\%) } \\
\hline Local breeds $^{\mathrm{a}}$ & 99.8 & 99.4 & 100.0 & 99.8 \\
\hline Exotic breeds ${ }^{\mathrm{b}}$ & 8.6 & 15.2 & 65.8 & 14.7 \\
\hline Hybrid breeds & 9.2 & 20.5 & 65.8 & 16.2 \\
\hline \multicolumn{5}{|l|}{ Feed ration composition (\%) } \\
\hline Forages only & 59.0 & 38.0 & 83.6 & 56.9 \\
\hline Forages + nutritional supplements & 41.0 & 62.0 & 16.4 & 43.1 \\
\hline Dietary supplements provision (\%) & 26.3 & 22.8 & 97.3 & 31.6 \\
\hline \multicolumn{5}{|l|}{ Prophylaxis practices (\%) } \\
\hline Pest control & 40.9 & 49.7 & 78.4 & 46.0 \\
\hline Vaccination & 70.9 & 89.5 & 61.6 & 73.8 \\
\hline \multicolumn{5}{|l|}{ Owned land for livestock (\%) } \\
\hline Less than 5 ha & 83.2 & 53.8 & 35.1 & 73.0 \\
\hline 5 ha and more & 16.8 & 46.2 & 64.9 & 27.0 \\
\hline
\end{tabular}


Table 2 Characteristics of cattle farm's types (Continued)

\begin{tabular}{|c|c|c|c|c|}
\hline & Type1 & Type2 & Type3 & Total \\
\hline Milk & 95.5 & 100.0 & 100.0 & 96.8 \\
\hline Meat & 72.5 & 98.8 & 98.6 & 79.1 \\
\hline \multicolumn{5}{|l|}{ Main farming objective (\%) } \\
\hline Savings & 48.9 & 26.4 & 75.0 & 44.9 \\
\hline Prestige & 5.6 & 0.0 & 0.0 & 4.5 \\
\hline Family subsistence & 45.6 & 73.6 & 25.0 & 50.6 \\
\hline \multicolumn{5}{|l|}{ Main destination of products (\%) } \\
\hline Self-consumption & 4.0 & 0.6 & 0.0 & 3.0 \\
\hline Sales & 96.0 & 99.4 & 100.0 & 97.0 \\
\hline \multicolumn{5}{|l|}{ Numerical composition of the herd } \\
\hline Herd size range & $1-40$ & $20-126$ & $41-182$ & $1-182$ \\
\hline Herd size & $6.3 \pm 6.7$ & $45.1 \pm 19.4$ & $78.1 \pm 28.1$ & $20.1 \pm 26.8$ \\
\hline Number of suckler cows & $1.2 \pm 1.8$ & $9.0 \pm 4.9$ & $37.2 \pm 11.8$ & $5.8 \pm 10.9$ \\
\hline Number of pregnant cows & $1.2 \pm 1.5$ & $6.2 \pm 4.3$ & $15.2 \pm 12.1$ & $3.4 \pm 5.9$ \\
\hline Number of sires & $1.0 \pm 1.0$ & $2.3 \pm 2.4$ & $5.9 \pm 4.6$ & $1.7 \pm 2.3$ \\
\hline Number of heifers & $1.0 \pm 1.7$ & $6.9 \pm 4.7$ & $4.7 \pm 4.6$ & $2.5 \pm 3.8$ \\
\hline Number of young sires & $0.4 \pm 1.0$ & $3.1 \pm 2.6$ & $6.4 \pm 3.3$ & $1.4 \pm 2.5$ \\
\hline Total number of calves & $0.8 \pm 1.2$ & $8.8 \pm 4.9$ & $4.3 \pm 2.1$ & $2.7 \pm 4.1$ \\
\hline Number of male calves & $0.4 \pm 0.7$ & $3.9 \pm 2.4$ & $1.9 \pm 0.9$ & $1.2 \pm 1.9$ \\
\hline Number of female calves & $0.4 \pm 0.7$ & $4.9 \pm 3.1$ & $2.4 \pm 1.7$ & $1.4 \pm 2.4$ \\
\hline Total number of cattle covered & 3909 & 7704 & 5699 & 17,312 \\
\hline Corresponding proportion (\%) & 22.6 & 44.5 & 32.9 & 100.0 \\
\hline \multicolumn{5}{|l|}{ Production } \\
\hline Weight of an adult (kg) & $261.5 \pm 56.2$ & $311.3 \pm 88.9$ & $362.3 \pm 87.3$ & $280.4 \pm 74.4$ \\
\hline Number of cattle sold annually & $1.2 \pm 1.2$ & $1.0 \pm 1.6$ & $2.4 \pm 1.4$ & $1.3 \pm 1.3$ \\
\hline Milk production/female/day (I) & $1.8 \pm 0.8$ & $1.7 \pm 0.7$ & $4.6 \pm 2.9$ & $2.9 \pm 1.4$ \\
\hline
\end{tabular}

aThe local cattle breeds encountered in South-Kivu are "Ankole cattle" and "N'Dama cattle", with a stronger predominance of the "Ankole cattle"

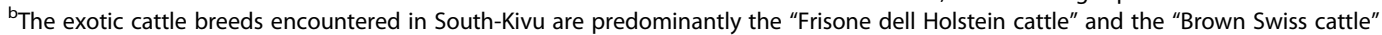

The ruminant production systems in SSA were classified into two main categories: traditional (pastoral, agropastoral and mixed) and non-traditional (ranching and dairy) systems (Otte and Chilonda 2002). Referring to Seré and Steinfeld (1996) criteria, the vast majority of cattle farms in South-Kivu can be considered to be of the pastoral type, since more than $90 \%$ of the dry matter served as cow feed comes from rangelands, pastures and annual forages. Generally, the feed of all cattle farms in South-Kivu province is mainly based on green forage found on different pastures. It is therefore obvious that all these farms, regardless of their type, are of the traditional type as described by the above-mentioned authors.

The most predominant cattle farms in South-Kivu are type 1 farms, defined by small herds of local breed animals not often exceeding 13 heads (six heads on average), which are found in both medium- and highaltitude areas. The size of landholding (less than 5 ha) appears to be a limiting factor in the numerical composition of cattle herds. Herd size reflects the wealth status of a household in pastoral communities (Omollo et al. 2018). Thus, farmers in this category are considered to have low wealth status. In South-Kivu, for most farmers, the less their landholding, the smaller their herds become. These areas of land owned by cattle farmers in South-Kivu are comparable with what is reported East Africa cattle farmers. In fact, McDermott et al. (2010) reported East African cattle farms to have less than 5 ha land, keeping one to five dairy cows that are often improved breed. Although landholding size varies considerably between countries, smallholder dairy farms have limited access to land. The average landholding size in the smallholder dairy sector is 4.65 ha in Kenya, 4.4 ha in Zimbabwe, 3.88 ha in Mozambique and 0.8 ha in Malawi (IFDC 2002; Ngongoni et al. 2006; Mulford 2013; Johnson et al. 2015). In Ethiopia, landholdings are generally small and increasingly fragmented, averaging less 
Table 3 Summary of the logit model and Poisson models of socio-economic determinants of adoption of exotic breeds and herd sizes

\begin{tabular}{|c|c|c|c|c|c|c|}
\hline \multirow[t]{2}{*}{ Source } & \multicolumn{3}{|c|}{ Adoption of exotic breeds } & \multicolumn{3}{|c|}{ Herds' size } \\
\hline & $\beta$ & S.E. & Prob $>x^{2}$ & $\beta$ & S.E. & Prob $>x^{2}$ \\
\hline Constant & -2.561 & 0.486 & $0.000^{* * *}$ & 2.610 & 0.038 & $0.000^{* * *}$ \\
\hline Experience in cattle farming & -0.018 & 0.013 & 0.166 & -0.004 & 0.001 & $0.000^{* * *}$ \\
\hline Age & 0.003 & 0.009 & 0.725 & -0.001 & 0.001 & 0.097 \\
\hline \multicolumn{7}{|l|}{ AEZ_-medium altitude } \\
\hline AEZ_high altitude & 0.678 & 0.243 & $0.005^{* *}$ & 0.255 & 0.019 & $0.000^{* * *}$ \\
\hline \multicolumn{7}{|l|}{ Sex-male } \\
\hline Sex-female & 0.631 & 0.389 & 0.099 & 0.213 & 0.031 & $0.000^{* * *}$ \\
\hline \multicolumn{7}{|l|}{ Marital status_-married } \\
\hline Marital status—divorced & -0.099 & 1.176 & 0.933 & -0.259 & 0.127 & $0.042^{*}$ \\
\hline Marital status_-widow & -0.129 & 1.342 & 0.923 & -1.750 & 0.260 & $0.000^{* * *}$ \\
\hline \multicolumn{7}{|l|}{ Education level_-illiterate } \\
\hline Education level_-primary & -0.246 & 0.327 & 0.452 & 0.563 & 0.025 & $0.000^{* * *}$ \\
\hline Education level_-secondary & 0.370 & 0.285 & 0.195 & 0.521 & 0.025 & $0.000^{* * *}$ \\
\hline Education level—university & 0.690 & 0.561 & 0.219 & 0.490 & 0.052 & $0.000^{* * *}$ \\
\hline \multicolumn{7}{|l|}{ Source of income-farming } \\
\hline Source of income-off-farm & 0.482 & 0.264 & $0.049^{*}$ & 0.063 & 0.022 & $0.005^{* *}$ \\
\hline \multicolumn{7}{|l|}{ Grazing system—herding } \\
\hline Grazing system—free-range & 0.887 & 0.265 & $0.001^{* * *}$ & 0.891 & 0.021 & $0.000^{* * *}$ \\
\hline Grazing system—zero-grazing & 0.054 & 0.338 & 0.873 & -0.075 & 0.031 & $0.016^{*}$ \\
\hline \multicolumn{7}{|l|}{ Owned land-less than 5 ha } \\
\hline \multirow[t]{2}{*}{ Owned land -5 ha and more } & 0.245 & 0.260 & 0.347 & 0.066 & 0.019 & $0.000^{* * *}$ \\
\hline & \multicolumn{3}{|c|}{$\begin{array}{l}\text { AUC }=0.699 \\
\operatorname{LR} X^{2}(13)=62.480 \\
\text { Prob }>X^{2}=0.000^{* * *} \\
\text { Log likelihood }=-329.279 \\
\text { Pseudo } R^{2}=0.087\end{array}$} & \multicolumn{3}{|c|}{$\begin{array}{l}\operatorname{LR} X^{2}(13)=2989.980 \\
\text { Prob }>X^{2}=0.000^{* * *} \\
\text { Log likelihood }=-12,403.11 \\
\text { Pseudo } R^{2}=0.108\end{array}$} \\
\hline
\end{tabular}

******: significant at alpha $=0.05,0.01$ and 0.001 , respectively

than a hectare (Dorosh and Rashid 2012). Tanzanian cattle farmers overwhelmingly identified land as the most important basic constraint they face (Baker et al. 2015). With increasing demographic growth, land is becoming scarcer and a highly coveted resource. Following an increasing demand for crops, grazing lands are gradually being turned into cropland (Oosting et al. 2014). The increasing pressure from farming activities, especially food crops, on available land and pastures has led to a continuous decline in owned livestock herd sizes, as well as less land dedicated to livestock farming and forage growing (Katongole et al. 2012). Therefore, the land shortage challenge involves, as one of the options, the sustainable intensification of smallholder dairy farming (Maleko et al. 2018). Land scarcity is one of the major constraints of catthe farming (Owen et al. 2012). For example, in Tanzania, the fear of smallholders of losing cultivated land to pasture has made the adoption of fodder crops very rare (Kavana et al. 2005; Kavana and Msangi 2005).
Increasing pressure on land presents cattle producers with the impossible challenge of choosing between growing food crops or grazing on limited units of land (Thornton 2010). The land around large cities is increasingly coveted for the expansion of the latter, making it more and more difficult to gain access to land compared to more remote geographical areas. Due to the small amount of land owned, cattle breeders surrounding large settlements raise small herds of cattle. Farmers in the surrounding of urban areas having mostly agriculture and/or herding as their main subsistence activity prefer to use the little space they have for growing forest species and/or food crops. This has also been reported in Uganda, where for farmers with similar poor land access, the small available lands are preferably used for food crops rather than forage/fodder growing (Katongole et al. 2012). These farmers are therefore unlikely to grow fodder crops, preferring to graze their animals on fallow land or community pastures, which are not maintained 
at all and, therefore, do not necessarily have good fodder species to meet animal nutrition requirements. For smallholder farmers, it is thus important to invest in practices that facilitate adaptation to increasingly limited land resources. Failure to adapt would restrict their ability to produce the quantities of food demanded by the rising populations (Bosire et al. 2019).

In most cattle farms in South-Kivu, animals are usually fed on community pastures, fallow land and roadside grasses since these areas are freely accessible. Fodder harvested from open access lands have been associated with the risk of tick-borne diseases and parasites (Katongole et al. 2012). In systems where cattle are grazed on common land, farmers are less interested in regularly treating their cattle against ticks since they are reinfested when in contact with untreated cattle in shared pastures (Pearson and Krecek 2006). Hence, the tick challenge on these lands is high. When farmers harvest the fodder, ticks are carried unintentionally with the harvested plants and introduced to their farms (Katongole et al. 2012). Since there is no maintenance of community pastures, this adversely affects fodder production, and in the long term, these pastures are no longer beneficial to the rearing of ruminants, especially cattle. It is therefore essential to apply management strategies for community pastures in view of their sustainable management. The biggest feeding constraint in all systems is a source of good-quality roughage. The dry climate found in most African countries makes it very difficult to grow goodquality grass. In most communal areas, pastures are not irrigated and certainly not fortified, so their nutritional value is very low during the dry season. Furthermore, the quality and quantity of fodder vary significantly throughout the year depending on the season (Stewart 2002). Fodder cultivation is an increasingly envisaged strategy for improving animal production, particularly beef production (Awa et al. 2003; Oosting et al. 2014; Omollo et al. 2018). Not only should fodder seeds be disseminated to farmers; there should be a follow-up by research and extension service to help them overcome difficulties in management and perpetuation of fodder species (Awa et al. 2003). Although this strategy is well-known to have several advantages, the small size of farms limits its adoption. In Uganda, dairy cattle farmers who had planted fodder on their farms were mostly those with relatively larger landholdings (Katongole et al. 2012). Therefore, the livestock-crop integrated farming systems have been shown to be economically advantageous in highly populated areas where land has become a limiting factor (Awa et al. 2003; Hendrickson et al. 2008; Wilkins 2008; Ryschawy et al. 2012). Thus, we believe that fodder cultivation should be encouraged by promoting livestock-crop integration approach as an agro-ecological cropping system where fodder is grown in association with food crops.
Farms of type 2 are mainly found in mid-altitude areas. In these farms, cows reared are essentially of the local breed. In this category, some farmers have large tracts of land, while others have small tracts of land with a herd size of 45 cattle. This type of cattle farming is an intermediate type between type 1 and type 3 farms. Type 3 farms appear to perform better than the other types. These farms are in the hands of the youngest farmers but also the least experienced in cattle farming. The cows bred there are mainly of local breeds, but very common to find exotic and crossbred breeds as well. This type of breeding is found generally in highlands (high-altitude areas), far away from big cities. The large land size reported in these areas is related to the fact that there is not much pressure on the land, as the breeders have enough space to allocate both grazing pasture, forest species and crops. This allows them to raise large numbers of cattle in paddocking systems. Cows are not housed as such. They are usually kept outside, as is frequently demonstrated in cattle farms in many parts of Africa (Stewart 2002). Although exotic breeds and crossbred can be found in type 3 herds, their production performances remain lower compared to their potentiality. Exotic breeds of dairy cows cannot meet their potential since their feeding is limited on unimproved grazing pastures. To increase their productivity in such an environment, they require being supplemented with concentrates and/or improved fodders (Stewart 2002). Similar to South-Kivu province, livestock feeding and husbandry in Babati (Tanzania) were reported to be mainly extensive, with relatively large herds of local cattle, few improved breeds, daytime grazing, little purchased feed, feeding on crop residues and low productivity (Paul et al. 2020).

Larger herds and higher stocking rates generally require a higher level of organization, infrastructure and skill to manage. The disease burden may be higher, and animals requiring individual intervention could be more difficult to identify and treat. Good planning and management skills are required to manage risks that have serious consequences (FAO 2011). Type 3 farms offer the advantage of having larger land areas that limit contact between animals on neighbouring farms. In addition to having large tracts of land at their disposal, cattle farms at high altitudes also have a seasonal advantage. The dry season is less severe, which means that the grass remains fresh all year round. Great variation in diversity and quantity of forage and other feed resources is related to rainfall. In areas with rainfall below $1000 \mathrm{~mm}$, pasture productivity is poor (Awa et al. 2003). In the study area, the high-altitude areas are characterized in particular by high rainfall throughout the year and offer favourable conditions for pasture. Cattle farmers subdivide their plots into paddocks for good feed management 
throughout the year. However, this does not necessarily guarantee a balanced diet for their cows. The pasture found in these environments is not necessarily of good quality. On most farms, cattle pasture consists of wild grasses such as those found on rangelands and fallow land.

Although smallholder cattle farming systems are characterized by low productivity, the major advantage is lower production costs due to the use of "low-tech" and reliance on cheap feeds, i.e. low-input-low-yield production systems (Hemme and Otte 2012). In such systems, the main feed is grass and crop residues which are considerably lower in cost than the predominantly imported grain which is fed to high-yielding dairy cows (high-input-high-yield) in the developed world (Maleko et al. 2018). Although genetic improvement of farmed livestock has a major impact on productivity, resource use efficiency and food security, in many tropical countries, including Kenya, the use of exotic breeds is generally discouraged under smallholder conditions because of their higher nutritional demand, low milk yield, poor adaptability and low production efficiency (see, e.g., Rege 1998; Kahi et al. 2000). Genetic improvement efforts have often relied on inappropriate exotic breeds, with the added disadvantage of marginalizing indigenous genetic resources (Chagunda et al. 2016). We suspect that low access to exotic breeds of cattle, their poor performance in the conditions of smallholders, their high nutritional demand and their sensitivity to tropical disease are major factors that can justify the low level of their adoption in South-Kivu province. Local breeds of cattle are more adapted to local conditions but are less productive than exotic breeds. For a better productivity of cattle farms, it is essential to develop strategies to improve and/or develop local breeds of cattle that are both adapted to the local environment and more productive regarding milk and meat. Furthermore, in order to compensate for the possible deficit in forage intake, farmers would have to supplement their cows' diet. However, Maass et al. (2012) stated that unaffordable prices for by-products and concentrates are among the major feeding constraints in livestock farming in South-Kivu province. Access to agricultural credit and the grouping of farmers in cooperatives are strategies through which these kinds of constraints can find sustainable solutions.

Apart from the distinguishing characteristics listed above, cattle farms in South-Kivu province display a number of common characteristics. Herds are held by men with an average age of $46.2 \pm 14.2$ years and rarely held by farmers less than 20 years of age. Most of them have primary and/or secondary training and live mainly from agriculture or animal husbandry. These farms are not of a specialized type. Their purpose is to produce both milk and meat for household subsistence. Apart from that, animals constitute savings that enable the farmers to cope with hazards and meet their social obligations linked to their customs.

Considering the gender aspect, women are less involved in livestock farming. This could be due to cultural beliefs, which recognize men as owners of large animals and the low level of women's emancipation in rural areas. Indeed, households often own livestock farms, which often implies that they are owned by households' heads, who are men from a cultural point of view. This is why livestock are often reported to be owned by male household heads. It is thus difficult to give an accurate picture of the level of women's involvement in cattle farming due to gender disparities or inequalities in livestock ownership (Njuki and Sanginga 2013). The situation of women in livestock farming in South-Kivu is similar to that of their counterparts in Nigeria and Ethiopia where the majority of women rarely participate in livestock production. Women in the agricultural sector are more involved in home production activities, which involve childcare, food preparation and carrying of water and fuel (Yisehak 2008; Ayoade et al. 2009).

The level of training of cattle farm owners is an opportunity for the improvement of the cattle production sector. Most of the farmers have at least secondary education, which gives them certain receptivity to the adoption of innovations and good breeding practices. $\mathrm{Al}$ though farmers have stated that they aim at both milk and meat production on their cattle farms, the structure of the herds shows more clearly that it is milk production that is the main objective of cattle farming.

\section{Conclusion}

The current typology study identifies three types of cattle farms that differ mainly in the size of their herds and the extent of their land ownership. Nevertheless, cattle farms of all types share many common characteristics, including the fact that they are extensive pastoral farms owned by male farmers who have agriculture and/or livestock farming as their main source of income and most of whom, in addition to cattle, also raise goats and/ or poultry. The main constraints to cattle farming in South-Kivu are land scarcity, low productivity of local breeds, unavailability of improved pasture and inadequate practices. Cattle production will remain low unless supported by an intensive production system. To meet the demand for beef and milk in spite of the increasingly limited access to land, it is necessary to support farmers in increased feed supply. This will be achieved through feed value chain development. Croplivestock integration through agro-ecological systems in which food crops are grown in association with fodder crops is one of the strategies that can maximize the use 
of space while restoring the soil. In addition, access to agricultural credit can also be an alternative to foster investment in livestock in South-Kivu. All this can only lead to better results though improved local market access to smallholder producers.

This work does not provide information on different pastures for cattle grazing. Further studies are needed to cover this gap.

\section{Acknowledgements}

The authors sincerely thank students from the Faculty of Agriculture and Environmental studies of the Université Evangélique en Afrique for their valuable contributions in data collection. Farmers are also acknowledged for their cooperation during data collection. The authors acknowledge the Université Evangélique en Afrique for support to this work through the university project on improvement of research and teaching quality funded by Pain pour le Monde (Project A-COD-2018-0383).

\section{Authors' contributions}

YM, RBBA and VBM contributed to the conception and design. YM, VBM, NCC and DSW contributed to the supervision of the fieldwork for data collection. YM, RBBA, VBM, NCC, DSW, PCA and KK contributed to the drafting of the manuscript. YM, RBBA, VBM, NCC, DSW, PCA and KK contributed to the designing of the study as well as analysis and interpretation of the data. YM, RBBA, VBM, NCC, DSW, PCA and KK contributed to the final editing and approval of the manuscript.

\section{Funding}

Not applicable

\section{Availability of data and materials}

The datasets used and/or analysed during the current study are available from the corresponding author on reasonable request.

\section{Ethics approval and consent to participate}

We have conducted this study adhering to the national and international standards governing research of this nature.

\section{Consent for publication}

Not applicable

\section{Competing interests}

The authors declare that they have no competing interests.

Received: 25 August 2020 Accepted: 14 November 2020

Published online: 19 March 2021

\section{References}

Akilimali, J.I., D.S. Wasso, P. Baenyi, and J.B. Bajope. 2017. Caractérisation des systèmes de production porcine de petits exploitants dans trois zones agroécologiques du Sud-Kivu en République Démocratique du Congo. Journal of Applied Biosciences 120: 12086-12097 https://doi.org/10.4314/jab.v120i1.11.

Alvarez, Stéphanie, Carl J. Timler, Mirja Michalscheck, Wim Paas, Katrien Descheemaeker, Pablo Tittonell, Jens A. Andersson, and Jeroen C.J. Groot. 2018. Capturing farm diversity with hypothesis-based typologies: An innovative methodological framework for farming system typology development. PLoS One 13: e0194757 https://doi.org/10.1371/journal.pone.0194757.

Awa D.N., Njoya A., Logtene Y.M., Ndomadji J.A., Onana J., Asongwed-Awa A., Tama C.A.N., Djoumessi M., Loko B., Bechir A.B., Delafosse A., Maho A. 2003. Livestock production systems in the semi-arid savannah of the Central African sub-region. Actes du Colloque, 27-31 mai 2002. Garoua: Cameroun; 2002. https://hal.archives-ouvertes.fr/hal-00137977/. Accessed 7 Mar 2020.

Ayoade, J.A., H.I. Ibrahim, and H.Y. Ibrahim. 2009. Analysis of women involvement in livestock production in Lafia area of Nasarawa State, Nigeria. Livestock Research for Rural Development 21. https://Irrd.cipav.org.co//rrd21/12/a yoa21220.htm. Accessed 21 Mar 2020.

Baker, Derek, Jo Cadilhon, and Washington Ochola. 2015. Identification and analysis of smallholder producers' constraints: Applications to Tanzania and Uganda. Development in Practice 25: 204-220 https:/doi.org/10.1080/09614524.2015.1007924.
Bosire, Caroline K., J. Rao, Voster Muchenje, Mark Van Wijk, Joseph O. Ogutu, Mesfin M. Mekonnen, Joseph Auma, Ben Lukuyu, and J. Hammond. 2019. Adaptation opportunities for smallholder dairy farmers facing resource scarcity: Integrated livestock, water and land management. Agriculture, Ecosystems and Environment 284 https://doi.org/10.1016/j.agee.2019.106592.

Chagunda, Mizeck G.G., Agnes Mwangwela, Chisoni Mumba, Filomena Dos Anjos, Bettie S. Kawonga, Richard Hopkins, and Linley Chiwona-Kartun. 2016. Assessing and managing intensification in smallholder dairy systems for food and nutrition security in Sub-Saharan Africa. Regional Environmental Change 16: 2257-2267 https://doi.org/10.1007/s10113-015-0829-7.

Cox, T. Paul. 2012. Farming the battlefield: The meanings of war, cattle and soil in South Kivu, Democratic Republic of the Congo. Disasters 36: 233-248 https:// doi.org/10.1111/j.1467-7717.2011.01257.x.

Davis, Benjamin, Stefania Di Giuseppe, and Alberto Zezza. 2017. Are African households (not) leaving agriculture? Patterns of households' income sources in rural SubSaharan Africa. Food Policy 67: 153-174 https://doi.org/10.1016/j.foodpol.2016.09.018.

Development Core Team, R. 2018. R statistical software. In R: A language and environment for statistical computing. Vienna: R Foundation for Statistical Computing.

Dorosh, Paul A., and Shahidur Rashid. 2012. Food and agriculture in Ethiopia: Progress and policy challenges. Philadelphia: University of Pennsylvania Press.

FAO. 2011. Guide to good dairy farming practice. Animal production and Health - Guidelines. No. 8. Rome: Food and Agriculture Organization of the United Nations and International Dairy Federation. http://www.fao.org/3/ba0027e/ba 0027e00.pdf. Accessed 21 Mar 2020.

Hair, Joseph F., William C. Black, and Barry J. Babin. 2010. Multivariate data analysis: A global perspective. London: Pearson Education.

Hemme, T., and J. Otte. 2012. Status of and prospects for smallholder milk production - A global perspective. Rome: Food and Agriculture Organization of the United Nations.

Hendrickson, John R., J.D. Hanson, Donald L. Tanaka, and Gretchen Sassenrath. 2008. Principles of integrated agricultural systems: Introduction to processes and definition. Renewable Agriculture and Food Systems 23: 265-271 https:// doi.org/10.1017/S1742170507001718.

Herrero, M., D. Grace, J. Njuki, N. Johnson, D. Enahoro, S. Silvestri, and M.C. Rufino. 2013. The roles of livestock in developing countries. Animal 7: 3-18 https:// doi.org/10.1017/S1751731112001954.

Husson, François, J. Josse, and J. Pages. 2010. Principal component methodshierarchical clustering-partitional clustering: Why would we need to choose for visualizing data? Rennes: Agrocampus Ouest, Applied Mathematics Department.

IFDC. 2002. An action plan for developing sustainable agricultural input supply systems in Malawi. Lilongwe: IFDC - An International Center for Soil Fertility and Agricultural Development.

Iraizoz, Belen, Matthew Gorton, and Sophia Davidova. 2007. Segmenting farms for analysing agricultural trajectories: A case study of the Navarra region in Spain. Agricultural Systems 93: 143-169 https://doi.org/10.1016/j.agsy.2006.05.002

Johnson, Nancy, Jemimah Njuki, Elizabeth Waithanji, Marinho Nhambeto, Martha Rogers, and Elizabeth Hutchinson Kruger. 2015. The gendered impacts of agricultural asset transfer projects: Lessons from the Manica Smallholder Dairy Development Program. Gender, Technology and Development 19: 145180 https://doi.org/10.1177/0971852415578041.

Kahi, A.K., W. Thorpe, G. Nitter, J.A.M. Van Arendonk, and C.F. Gall. 2000. Economic evaluation of crossbreeding for dairy production in a pasture based production system in Kenya. Livestock Production Science 65: 167-184 https:// doi.org/10.1016/S0301-6226(99)00154-2.

Kandala, Ngianga Bakwin, Tumwaka P. Madungu, Jacques B.O. Emina, Kikhela P.D. Nzita, and Francesco P. Cappuccio. 2011. Malnutrition among children under the age of five in the Democratic Republic of Congo (DRC): Does geographic location matter? BMC Public Health 11 https:/doi.org/10.1186/1471-2458-11-261.

Katongole, Constantine Bakyusa, Justine Nambi-Kasozi, Richard Lumu, Felix Bareeba, Magdalena Presto, Emma Ivarsson, and Jan Erik Lindberg. 2012. Strategies for coping with feed scarcity among urban and peri-urban livestock farmers in Kampala, Uganda. Journal of Agriculture and Rural Development in the Tropics and Subtropics 113: 165-174.

Kavana, P.Y., J.B. Kizima, Y.N. Msanga, N.B. Kilongozi, B.S.J. Msangi, L.A. Kadeng'uka, S. Mngulu, and P.K. Shimba. 2005. Potential of pasture and forage for ruminant production in eastern zone of Tanzania. Livestock Research for Rural Development 17. http://www.lrrd.org//rrd17/12/kava17144.htm. Accessed 21 Mar 2020.

Kavana, P.Y., and B.S.J. Msangi. 2005. On farm dairy cattle feeding experience in eastern zone of Tanzania. Livestock Research for Rural Development 17. http:// www.Irrd.org//rrd17/6/kava17062.htm. Accessed 21 Mar 2020. 
Kuivanen, K.S., S. Alvarez, M. Michalscheck, S. Adjei-Nsiah, K. Descheemaeker, S. Mellon-Bedi, and J.C.J. Groot. 2016. Characterising the diversity of smallholder farming systems and their constraints and opportunities for innovation: A case study from the Northern Region, Ghana. NJAS - Wageningen Journal of Life Sciences 78: 153-166 https://doi.org/10.1016/j.njas.2016.04.003.

Lammers, Peter J., Sarah L. Carlson, Gretchen A. Zdorkowski, and Mark S. Honeyman. 2009. Reducing food insecurity in developing countries through meat production: The potential of the guinea pig (Cavia porcellus). Renewable Agriculture and Food Systems 24: 155-162 https://doi.org/10.1017/ S1742170509002543.

Lê, Sébastien, Julie Josse, and François Husson. 2008. FactoMineR: An R package for multivariate analysis. Journal of Statistical Software 25: 1-18 https://doi. org/10.18637/jss.v025.i01.

Maass, Brigitte L., Dieudonné Katunga Musale, Wanjiku L. Chiuri, Anja Gassner, and Michael Peters. 2012. Challenges and opportunities for smallholder livestock production in post-conflict South Kivu, eastern DR Congo. Tropical Animal Health and Production 44: 1221-1232 https://doi.org/10.1007/s11250-011-0061-5.

Maleko, David, George Msalya, Angello Mwilawa, Liliane Pasape, and Kelvin Mtei. 2018. Smallholder dairy cattle feeding technologies and practices in Tanzania: Failures, successes, challenges and prospects for sustainability. International Journal of Agricultural Sustainability 16: 201-213 https://doi.org/1 0.1080/14735903.2018.1440474.

McDermott, J.J., S.J. Staal, H.A. Freeman, M. Herrero, and J.A. Van de Steeg. 2010. Sustaining intensification of smallholder livestock systems in the tropics. Livestock Science 130: 95-109 https://doi.org/10.1016/j.livsci.2010.02.014.

Michielsens, C.G.., K. Lorenzen, M.J. Phillips, and R. Gauthier. 2002. Asian carp farming systems: Towards a typology and increased resource use efficiency. Aquaculture Research 33: 403-413 https://doi.org/10.1046/j.1365-2109.2002.00686.x

Mugumaarhahama, Yannick, Rodrigue Basengere Balthazar Ayagirwe, Valence Bwana Mutwedu, Jack Mutarushwa Sadiki, Patrick Baenyi, Aarsène Ciza Mushagalusa, and Espoir Bisimwa Bisimwa. 2016. Caractérisation des systèmes de production de poule locale dans deux zones agro-écologiques du Sud-Kivu (République Démocratique du Congo). Livestock Research for Rural Development 28. http://www.Irrd.org//rrd28/1/mugu28007.html. Accessed 13 Mar 2020.

Mugumaarhahama, Yannick, Valence Bwana Mutwedu, Léonard Muzee Kazamwali, Arsène Ciza Mushagalusa, Fabrice Kwankanaba Bantuzeko, Serge Shakanye Ndjadi, Adrien Byamungu Ndeko, Nadège Cizungu Cirezi, Pascaline Ciza Azine, and Basengere-balthazar Ayagirwe. 2020. Typology of smallholder's pig production systems in South Kivu, Democratic Republic of Congo: Challenges and opportunities. Journal of Agriculture and Rural Development in the Tropics and Subtropics 121: 135-146 https://doi.org/10.17170/kobra-202005281301.

Mulford, Michael R. 2013. Smallholder market participation and welfare effects: Evidence from the Kenya dairy sector. MSc thesis, Ithaca: Cornell University.

Mutwedu, Valence Bwana, Rodrigue Basengere Balthazar Ayagirwe, Kalimira Thierry Metre, Yannick Mugumaarhahama, Jack Mutarushwa Sadiki, and Espoir Basengere Bisimwa. 2015. Systèmes de production cunicole en milieu paysan au Sud-Kivu, Est de la RD Congo. Livestock Research for Rural Development 27. http://www.lrrd.org//rrd27/10/mutw27206.html. Accessed 23 Mar 2020.

Mutyasira, Vine. 2020. Prospects of sustainable intensification of smallholder farming systems: A farmer typology approach. African Journal of Science, Technology, Innovation and Development 12: 727-734.

Ngongoni, N.T., C. Mapiye, M. Mwale, and B. Mupeta. 2006. Factors affecting milk production in the smallholder dairy sector of Zimbabwe. Livestock Research for Rural Development 18. https:///rrd.cipav.org.co//rrd18/6/ngon18089.htm. Accessed 18 Mar 2020.

Njuki, Jemimah, and Pascal C. Sanginga. 2013. Gender and livestock: key issues, challenges and opportunities. In Women, Livestock Ownership and Markets: Bridging the gender gap in Eastern and Southern Africa, eds J. Njuki and P. C. Sanginga. New York: Routledge.

Omollo, Erick Ouma, Oliver Vivian Wasonga, Mohammed Yazan Elhadi, and William Ngoyawu Mnene. 2018. Determinants of pastoral and agropastoral households' participation in fodder production in Makueni and Kajiado counties, Kenya. Pastoralism 8 https://doi.org/10.1186/s13 570-018-0113-9.

Oosting, S.J., H.M.J. Udo, and T.C. Viets. 2014. Development of livestock production in the tropics: Farm and farmers' perspectives. Animal 8: 12381248 https://doi.org/10.1017/S1751731114000548.

Otte, M.J., and P. Chilonda. 2002. Cattle and small ruminant production systems in sub-Saharan Africa: A systematic review. Rome: Food and Agriculture Organization of the United Nations.
Owen, Emyr, Tim Smith, and Harinder Makkar. 2012. Successes and failures with animal nutrition practices and technologies in developing countries: A synthesis of an FAO e-conference. Animal Feed Science and Technology 174 211-226. https://doi.org/10.1016/j.anifeedsci.2012.03.010.

Paul, Birthe K., Jeroen C.J. Groot, Celine A. Birnholz, Nzogela Beatus, A. Notenbaert, Kassahun Woyessa, Rolf Sommer, Ravic Nijbroek, and Pablo Tittonell. 2020. Reducing agro-environmental trade-offs through sustainable livestock intensification across smallholder systems in northern Tanzania. International Journal of Agricultural Sustainability 18: 35-54 https://doi.org/1 0.1080/14735903.2019.1695348.

Pearson, R.A., and R.C. Krecek. 2006. Delivery of health and husbandry improvements to working animals in Africa. Tropical Animal Health and Production 38: 93-101 https://doi.org/10.1007/s11250-006-4363-y.

Rege, J.E.O. 1998. Utilization of exotic germplasm for milk production in the tropics. In Proceedings of the 6th World Congress on Genetics Applied to Livestock Production 25:193-200, 11-16 January 1998. Armidale: University of New England.

Reynolds, A.P., G. Richards, B. De La Iglesia, and V.J. Rayward-Smith. 2006. Clustering rules: A comparison of partitioning and hierarchical clustering algorithms. Journal of Mathematical Modelling and Algorithms 5: 475-504 https://doi.org/10.1007/s10852-005-9022-1.

Rossi, Laura, Thomas Hoerz, Veronique Thouvenot, Gianni Pastore, and Markus Michael. 2006. Evaluation of health, nutrition and food security programmes in a complex emergency: The case of Congo as an example of a chronic post-conflict situation. Public Health Nutrition 9: 551-556 https://doi.org/10.1 079/PHN2005928.

Ryschawy, J., N. Choisis, J.P. Choisis, A. Joannon, and A. Gibon. 2012. Mixed croplivestock systems: An economic and environmental-friendly way of farming? Animal 6: 1722-1730 https://doi.org/10.1017/S1751731112000675.

Seré, C., A. Ayantunde, A. Duncan, A. Freeman, M. Herrero, S. Tarawali, and I. Wright. 2008. Livestock production and poverty alleviation - challenges and opportunities in arid and semi-arid tropical rangeland based systems. In Multifunctional Grasslands in a Changing World 1: 19- 26, XXI International Grassland Congress and VIII International Rangeland Congress, Hohhot, China, 29 June -5 July 2008. Guangzhou: Guangdong People's Publishing House.

Seré, C., and H. Steinfeld. 1996. World livestock production systems: Current status, issues and trends. In Animal production and health paper 127. Rome: Food and Agriculture Organization of the United Nations.

SNSA. 2014. Plan national d'investissement agricole (PNIA) 2014-2020. Kinshasa: Service National des Statistiques Agricoles - Ministère National de l'agriculture.

Stewart, R.J.E. 2002. Dairy production in diverse regions: Africa. In Fuquay JW, Fox PF, MCSweeney PLH, editors. Encyclopedia of dairy sciences, 2 nd ed., 77-82. London: Academic Press. https://doi.org/10.1016/B978-0-12-374407-4.00125-4.

Swanepoel, F.J.C., Stroebel, A. and Moyo, S., 2010. The role of livestock in developing communities: Enhancing multifunctionality. Cape Town: University of the Free State and CTA.

Thornton, Philip K. 2010. Livestock production: Recent trends, future prospects. Philosophical Transactions of the Royal Society, B: Biological Sciences 365 2853-2867 https://doi.org/10.1098/rstb.2010.0134.

Wiggins, S. 2009. Can the smallholder model deliver poverty reduction and food security for a rapidly growing population in Africa? Paper for the expert meeting on how to feed the world in 2050. Rome: Food and Agriculture Organization of the United Nations.

Wilkins, R.J. 2008. Eco-efficient approaches to land management: A case for increased integration of crop and animal production systems. Philosophical Transactions of the Royal Society, B: Biological Sciences 363: 517-525 https:// doi.org/10.1098/rstb.2007.2167.

Yisehak, Kechero. 2008. Gender responsibility in smallholder mixed crop-livestock production systems of Jimma zone, south West Ethiopia. Livestock Research for Rural Development 20. http://www.Irrd.org//rrd20/1/yise20011.htm Accessed 23 March 2020.

\section{Publisher's Note}

Springer Nature remains neutral with regard to jurisdictional claims in published maps and institutional affiliations. 